\title{
Fotografía y propaganda política: repercusiones en el arte de posguerra
}

\author{
Juan Daniel TAmayo Pozueta \\ Universidad del País Vasco
}

\begin{abstract}
RESUMEN
El artículo aborda el problema de la relación entre el discurso histórico-social y el discurso publicitario y la fotografía haciendo hincapié en los elementos básicos que configuran las principales ideologías que preparan la Segunda Guerra Mundial y su representación gráfica. Asimismo, el autor desarrolla las distintas formas de discurso posteriores al acontecimiento histórico que reflejan nuevas iniciativas artísticas relacionadas con posiciones pro y antibelicistas.
\end{abstract}

Palabras clave: Fotografía, propaganda política, arte, Segunda Guerra Mundial.

\section{Photography, Political Propaganda and their Afthermath in Postwar Art}

\begin{abstract}
This paper explores the problem of the relationships among socio-historic discourse, advertising and photography, paying special attention to the basic elements configuring the main ideologies at stake during World War II and its graphic representation. Moreover, the author develops the different forms of discourse following World War II that reflect new artistic initiatives related to pro and anti-war positions.
\end{abstract}

KEYwORDS: Photography, Political Propaganda, Art, World War II.

Difícil nos resulta imaginar la etapa vivida en muchos aspectos entre el final del siglo XIX y el primer tercio del XX. En el ámbito de las artes -más en concreto, en las artes plásticas- se sucede un torbellino de modos expresivos fruto de, por un lado, el advenimiento de nuevas ideologías y, por otro, la llegada de la imagen tecnológica de la fotografía en general y la cámara portátil en particular. Esta nueva tecnología, por si misma, cuestiona no solo la hegemonía de la pintura en las artes visuales sino incluso la pervivencia de la misma. El valor de la pintura como inequívoco medio de representación de la realidad se viene abajo. 
Los pintores más inquietos e inventivos tienen varias salidas a esta nueva situación:

- Huida hacia delante, pudiendo ser por ello tildados de anacrónicos y reaccionarios.

- Descomposición del orden clásico entre fondo y figura dentro del cuadro.

- Abandono del territorio virtual del cuadro y proyección sobre el espacio habitable tridimensional, con aproximación a la arquitectura y la escenografía.

- Alistamiento en la fotografía o/y el cine.

La fotografía y el cinematógrafo adquieren pronto relevancia dentro de la sociedad como instrumento más verídico y objetivo para retratar la realidad, sin los aditamentos subjetivos propios del dibujo, grabado, pintura. Su difusión cotidiana en la prensa propicia su popularidad. «La cámara estaba ahí» es garantía de certeza.

El oficio de fotógrafo era al comienzo ejercido con cámaras voluminosas que, aunque dentro del estudio eran fácilmente manejables, en los espacios abiertos su empleo era lento y dificultoso.

Será esta circunstancia la que desarrolle en apenas dos décadas una sofisticada ingeniería tanto en el campo de la óptica como de la mecánica de las cámaras.

Esto permitirá elevar a la categoría de mitos a modelos como: Vest pocket Kodak (1914), Rolleiflex (1920), Fed 1934, y las Speed Graphic, Contax, Kine Exacta Jhagee y Leica (1936), entre otras.
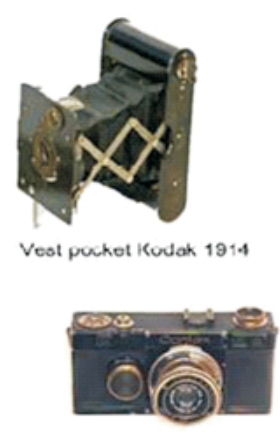

Leica 1936

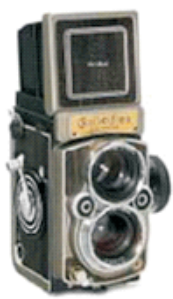

Rolleiflex 1929

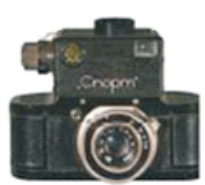

FED 1934

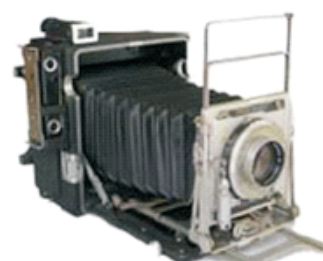

Speed Graphic 1936

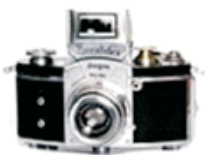

Tal avance hace posible que el fotógrafo se desenvuelva ágilmente dentro del corazón de los acontecimientos, incluso de aquellos que conllevan peligro. El corresponsal gráfico toma carta de naturaleza con un marcado tinte heroico; hace posible con su valor que los conflictos se visualicen a través de sus fotogramas, que sus audaces tomas, obtenidas en el campo de batalla, lleguen a la ciudadanía mediante carteles, prospectos, revistas, periódicos, etc. 

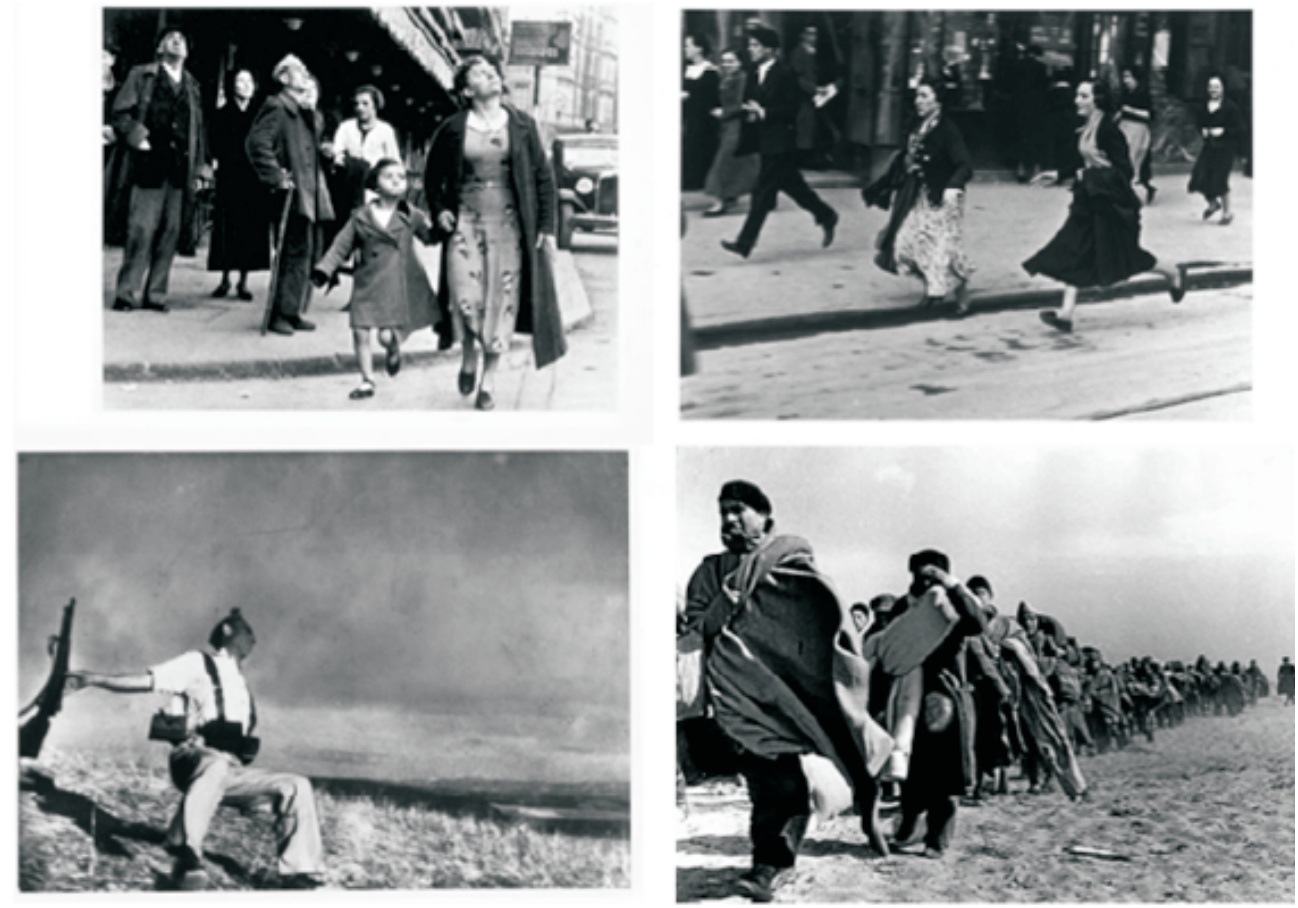

Escenas de la guerra civil española

Paralelamente y dentro del mundo del arte, un sector de la crítica comienza a explorar los valores estéticos, tanto de la fotografía como del cine, que en 1911 es denominado «El séptimo arte».
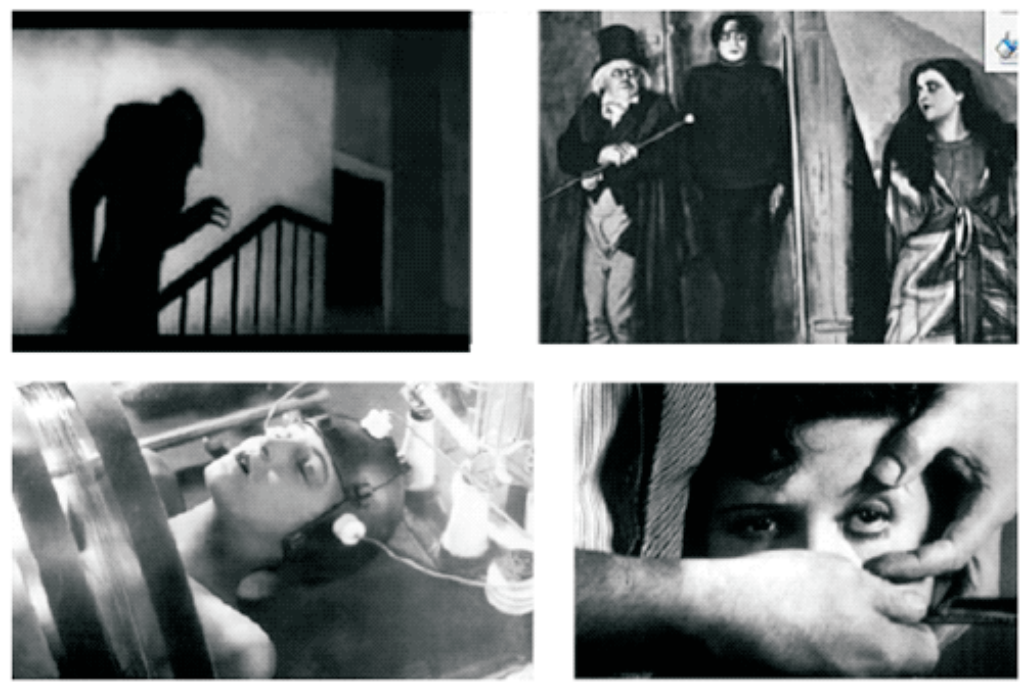

Fotogramas de Nosferatu, El gabinete del Dr. Caligari, Metropolis y el Perro andaluz

Revista de Filología Románica

2016, Vol. 33, Número Especial, 283-292 
La fotografía de índole artística fue propiciada en gran medida por corrientes eclécticas y pluridisciplinares como el Dadaísmo y el Surrealismo. Sus exponentes más reconocidos en el periodo de las vanguardias son Hannah Hoch, John Heartfield, Alexandr Rodchenko, Raoul Hausmann, Herbert Bayer, Man Ray, Gustav Klutsis, Moholy Nagi, Josep Renau, y Lissitzky, entre otros. Actualmente sus frutos se pue-den admirar en los museos al mismo nivel que cualquier otra modalidad artística.
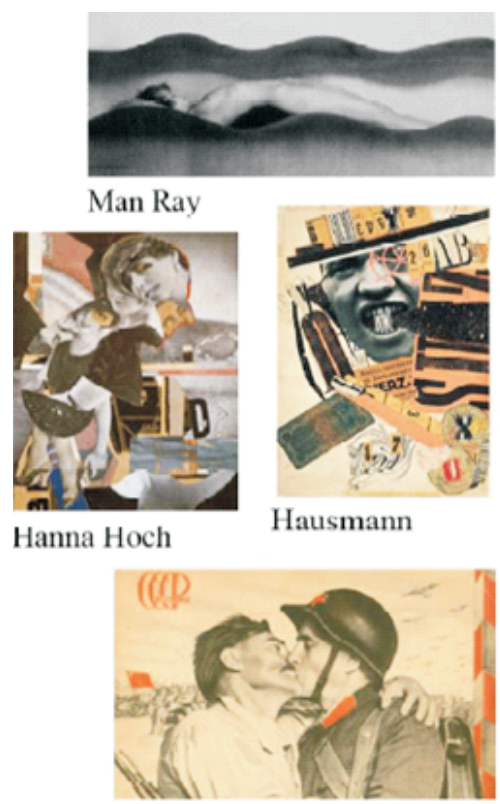

El Lissitzky

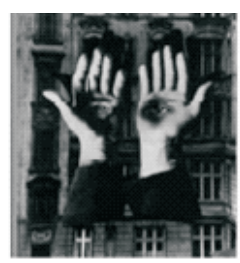

Bayer

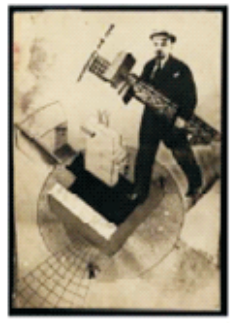

Klutsis

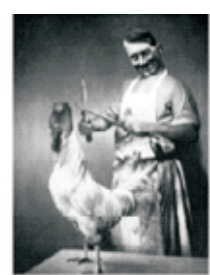

Heartfield

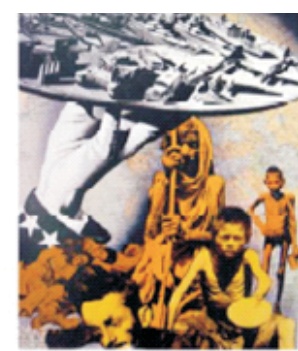

Renau

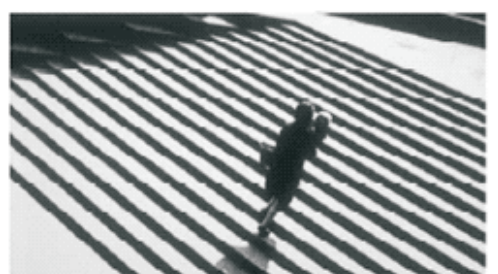

Rodchenko

Esta presencia de la imagen fotográfica va a dar lugar a un nuevo formato de la figuración, donde el artista aprehende la realidad ya no tanto por su órgano visual sino utilizando las revelaciones capturadas a través del objetivo de la cámara. La posterior manipulación de estas da lugar a una nueva era de modalidades expresivas.

La propaganda política será su principal campo de pruebas donde se exploren nuevas retóricas visuales. Se abre así un periodo de nueva propaganda, donde la imagen fotográfica cobra un papel relevante. 

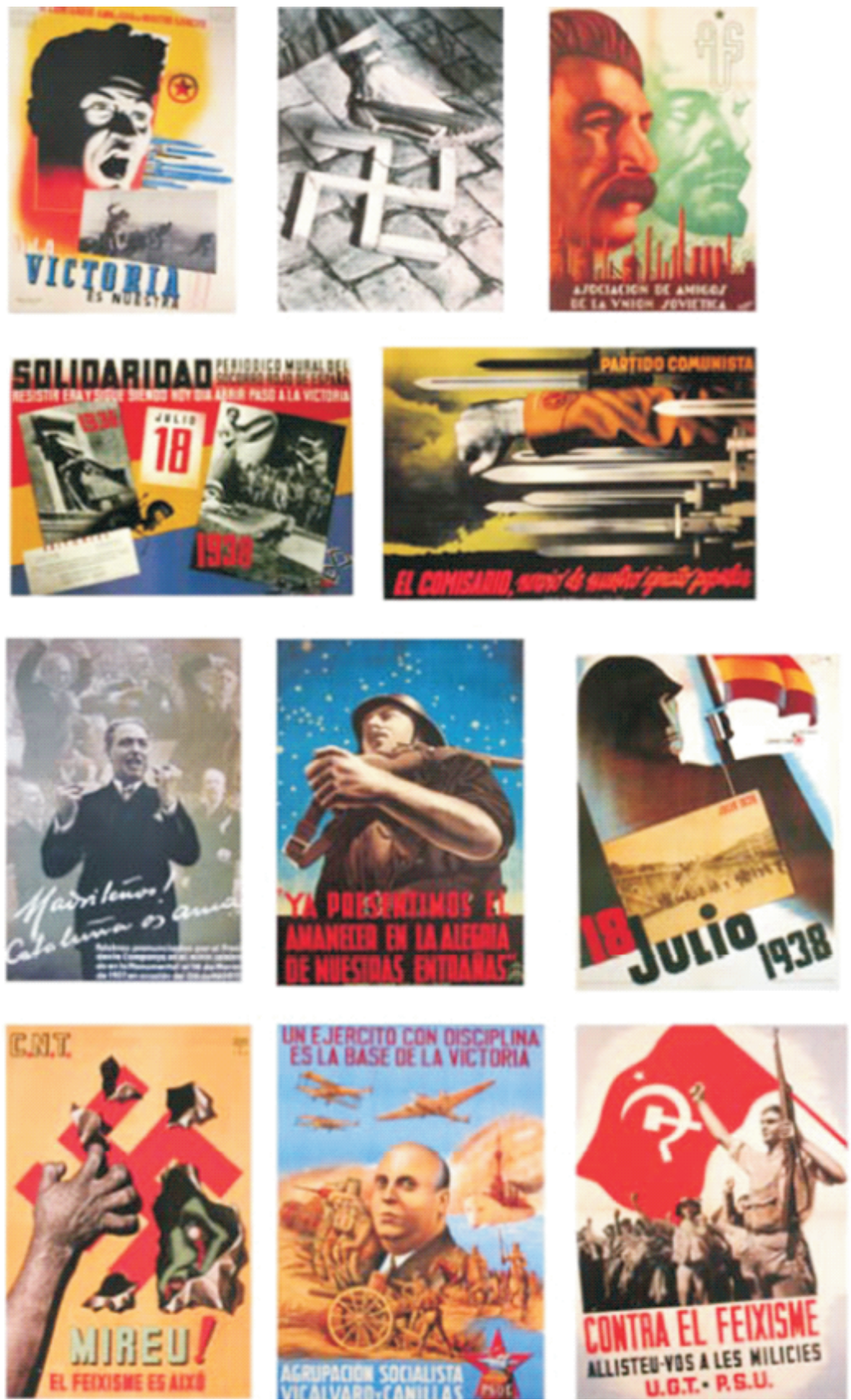

Estamos ante una retórica inédita, de enorme eficacia para el adoctrinamiento de las masas ante acontecimientos sociales de envergadura. En estos mensajes se conjugan el texto y la imagen provocando en el espectador una sumisión a la causa del 
emisor. Se desarrolla para ello un sinfín de fórmulas derivadas de la fotografía junto a las nuevas técnicas del diseño, maquetación e impresión gráfica, que tendrán una enorme repercusión en posteriores movimientos artísticos de posguerra.
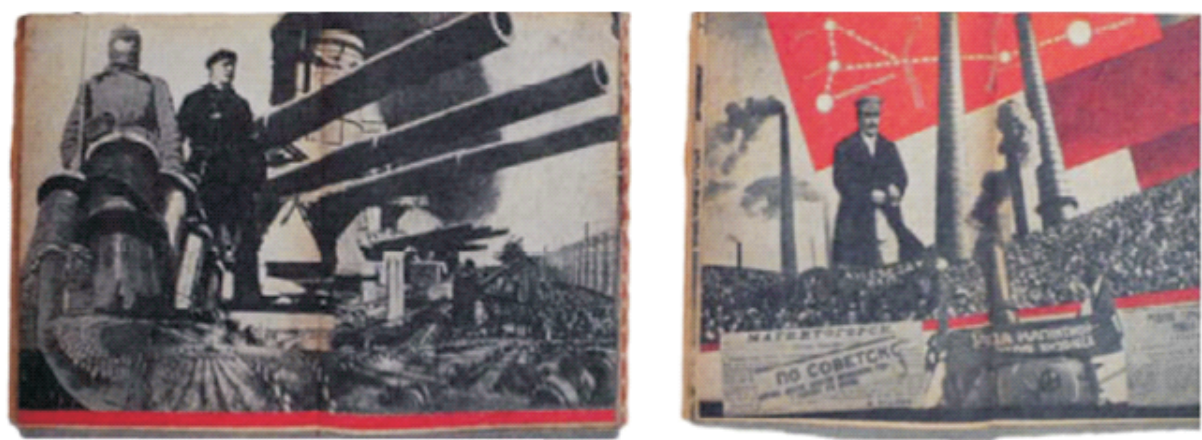

Propaganda de la URSS
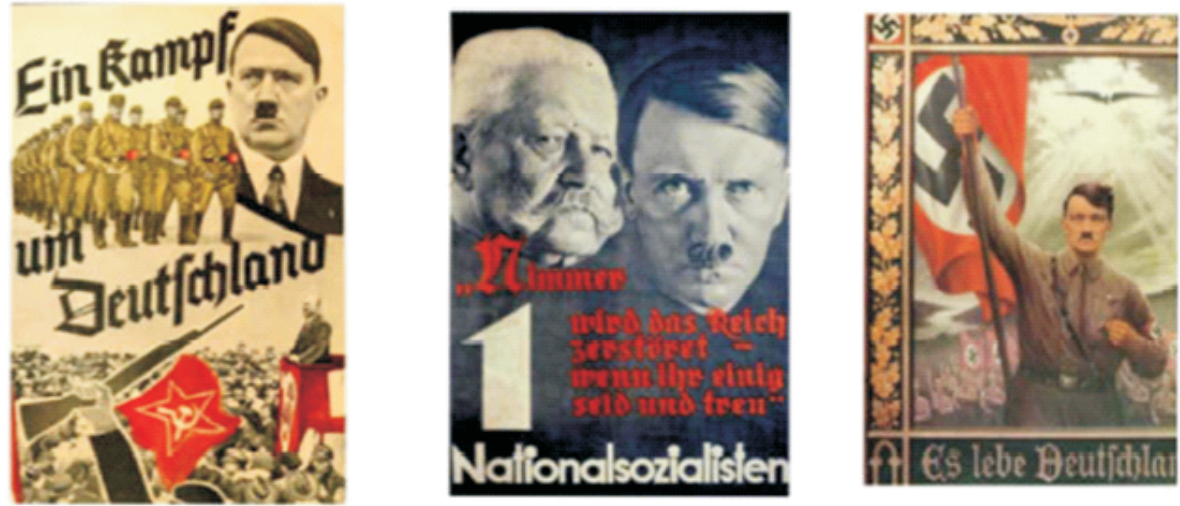

Propaganda del Tercer Reich

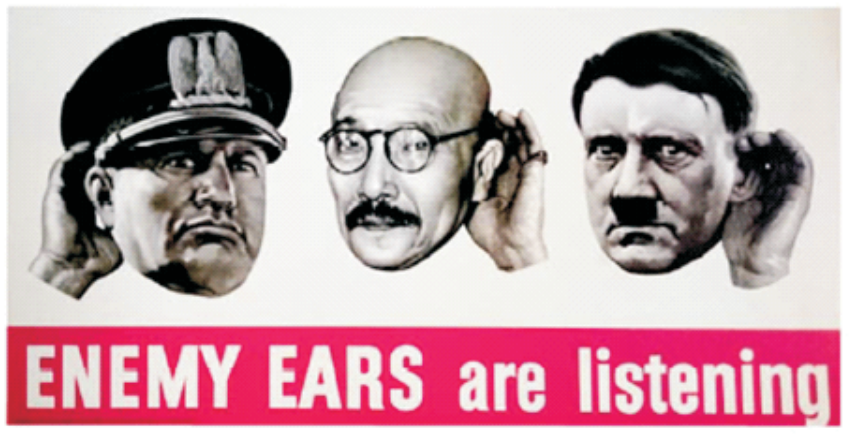

Propaganda aliada 
Este florecimiento de modos expresivos, considerados como ilustrativos de ideas, a veces incluso panfletarios será el germen de una nueva manera de entender el cuadro pictórico, ya no basado en la mera contemplación de la naturaleza o el modelo de estudio, pues la fotografía y ulterior manipulación se convertirá en la base documental para cualquier composición figurativa.
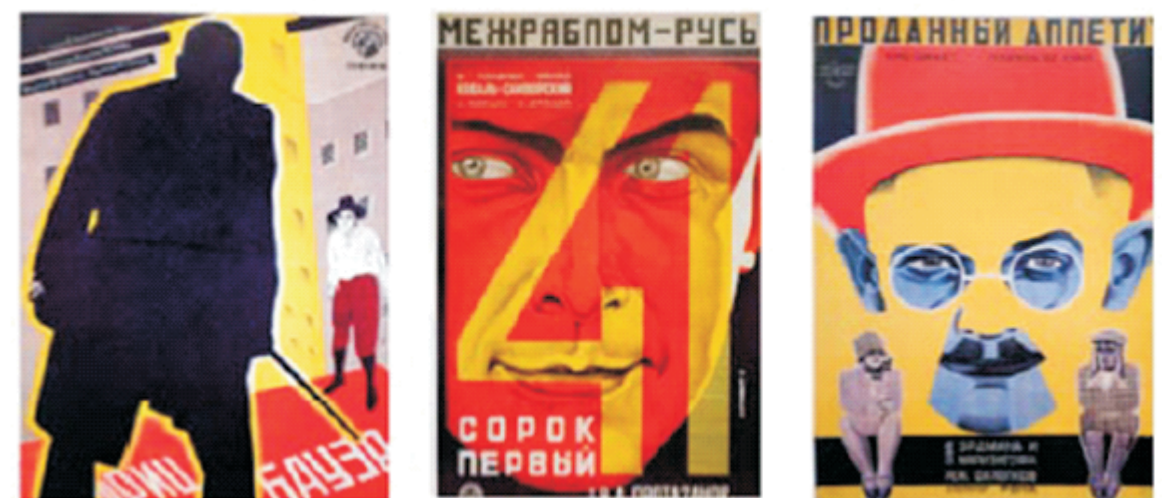

Los pintores vanguardistas con una retórica figurativa clásica emplean técnicas propias del renacimiento pero con unos encuadres tomados del cine y la fotografía. La óptica con sus múltiples lentes, las poses de los actores, la iluminación artificial y la ubicación de las cámaras de cine en posiciones forzadas (picado, contrapicado, primeros planos) aportan al espectador visiones de la realidad insólitas que no pasan desapercibidas para los pintores.

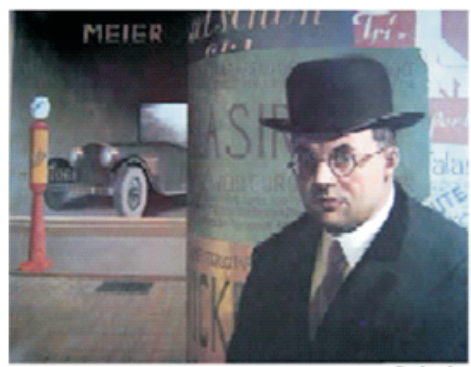

Scholz
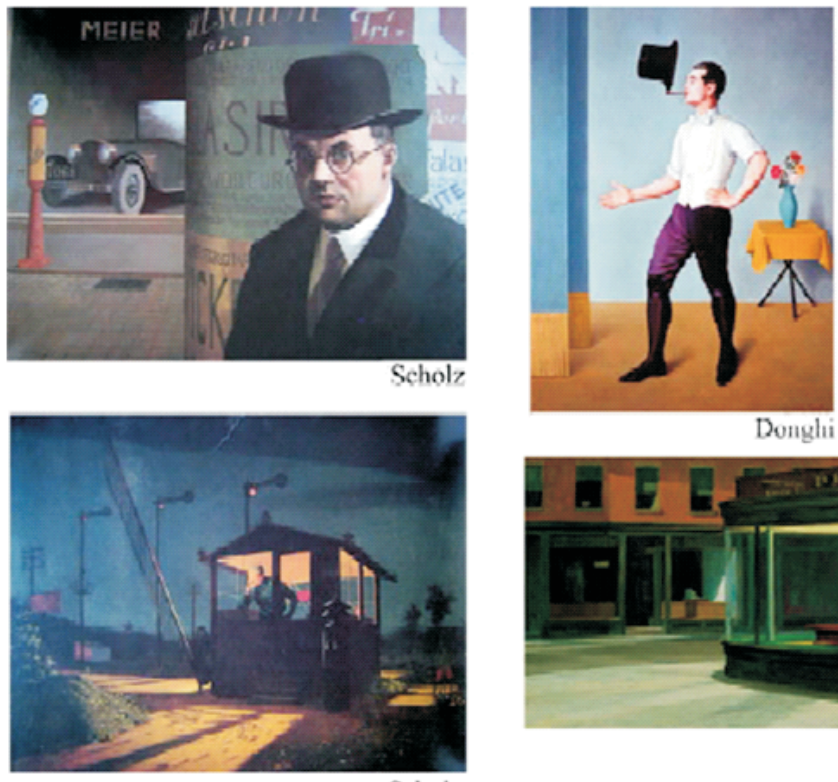

Donghii

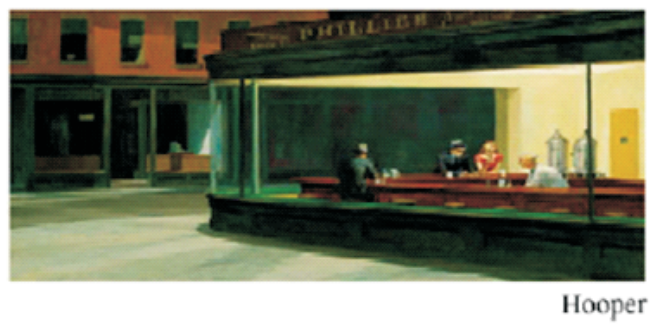

Scholz

Revista de Filología Románica 
Señalemos, en esta línea neo-figurativa del periodo de entreguerras, a los pintores Georg Scholz, Gran Wood, Ponce de León, Antonio Donghi y Edward Hopper.

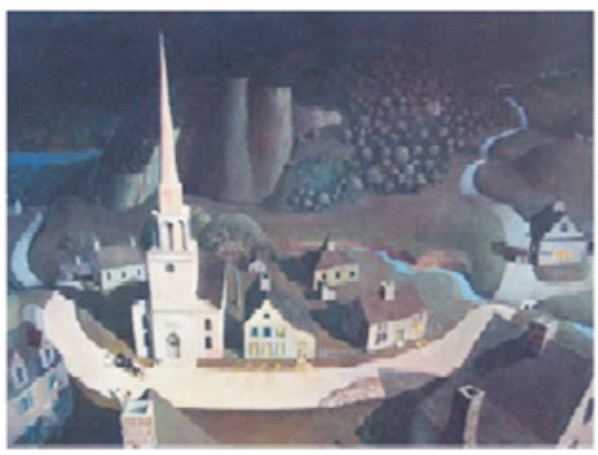

Wood

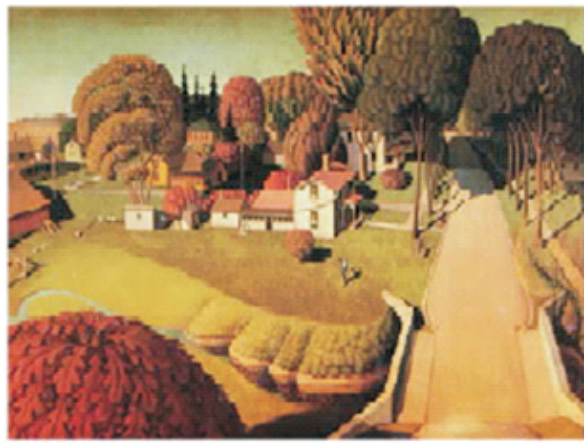

Wood

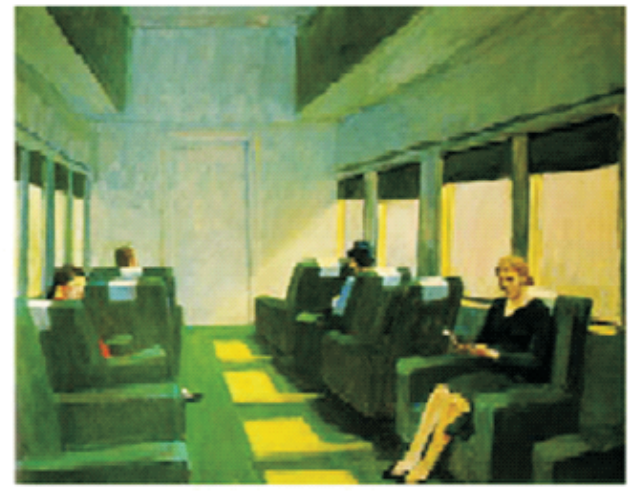

Hooper

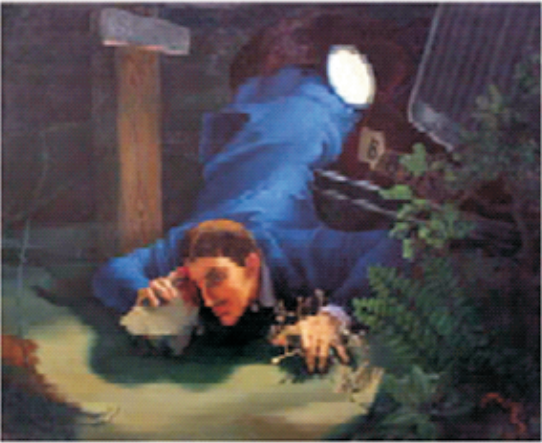

Ponce de León

Pero no será hasta la década de los 60 cuando esta etapa experimental con las nuevas imágenes irrumpa decididamente en el terreno propio de la pintura y como contestación a un periodo dominado por la pintura abstracta, tanto formalista como informalista.

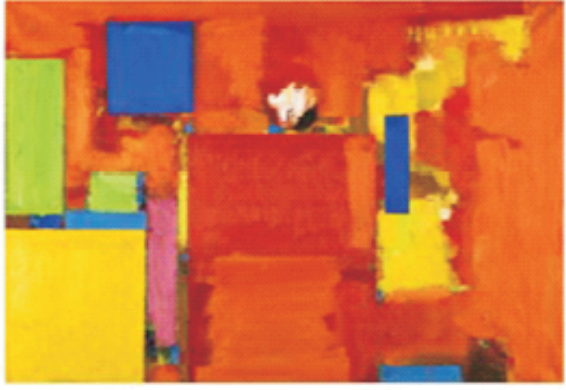

Hoffman

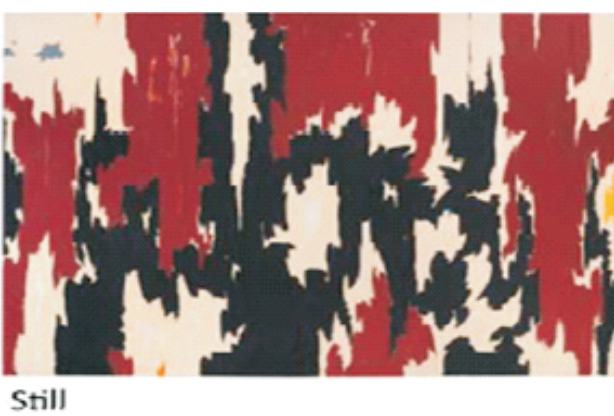

Revista de Filología Románica 2016, Vol. 33, Número Especial, 283-292 
Hay una franja histórica de ausencia de plástica narrativa que va del final de la Segunda Guerra Mundial (Hiroshima y Nagasaki) hasta finales de los años cincuenta cuando vuelven aparecer tímidamente figuras en los cuadros.
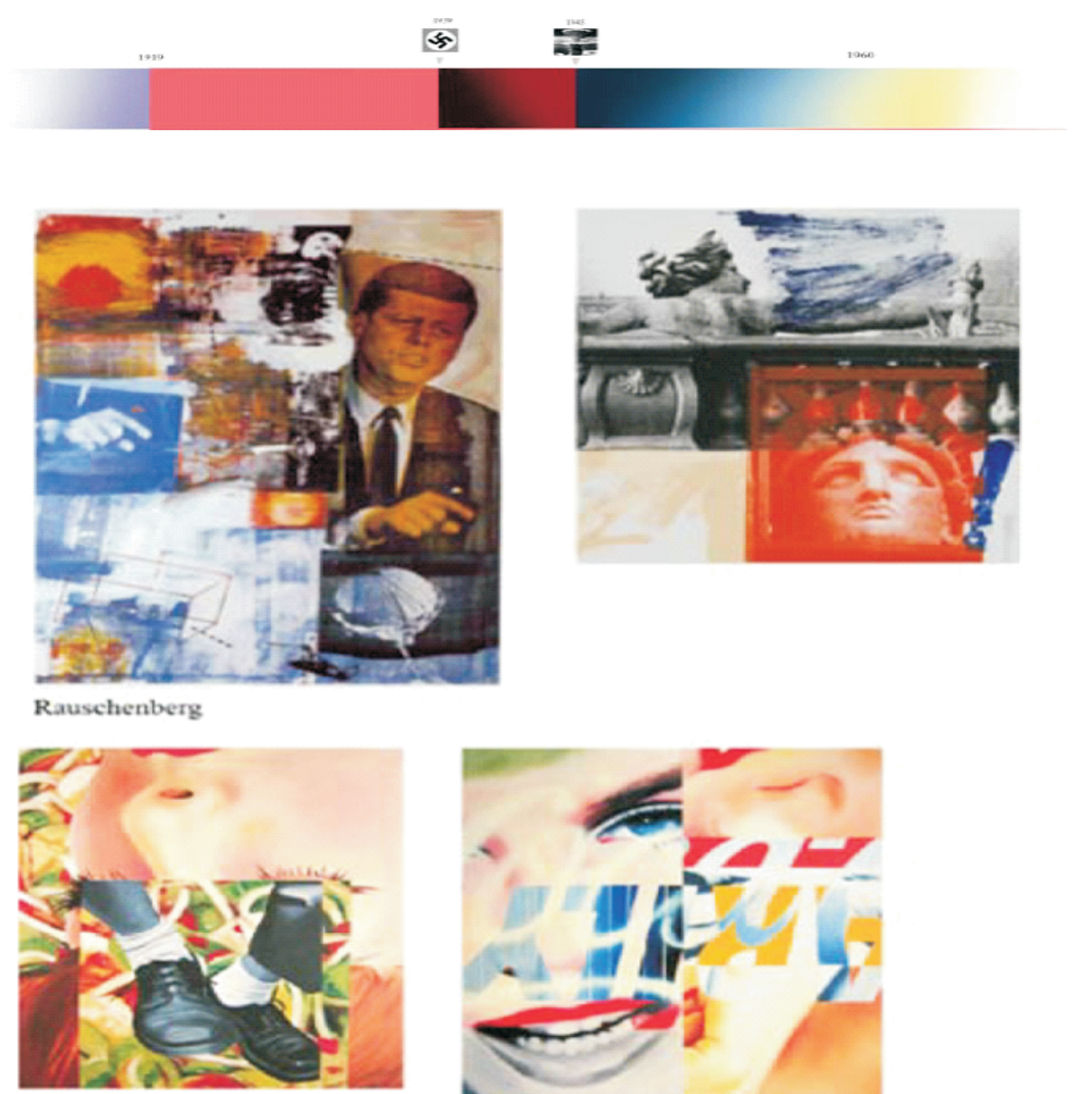

Rosenquist

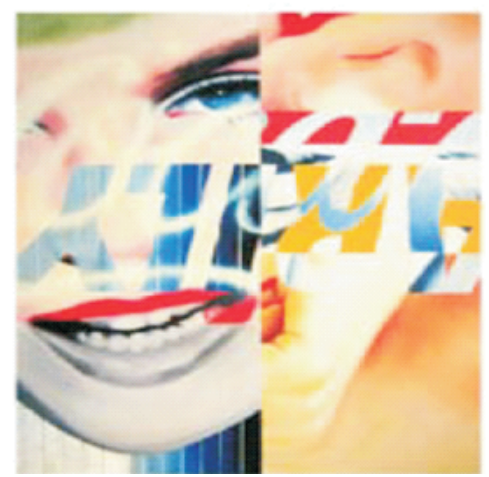

La fotografía hasta entonces era considerada un instrumento que finiquitaba [¿no será mejor «degradaba» o menoscababa»?] la pintura en todos sus géneros: retrato, bodegón, escenas públicas, paisajes, etc. Por obvia paradoja, la pintura figurativa será salvada a la postre por la fotografía, dado el uso que de la misma hace la figuración sintética del Arte Pop. Algo semejante ha ocurrido hace poco con la llegada de la era digital. Entonces, igualmente, se vuelve a sentenciar de muerte a la pintura. Pero nuevamente las formas surgidas de los software gráficos darán lugar a otras formas de modelar las figuras que muchos artistas han trasladado al soporte pictórico. 


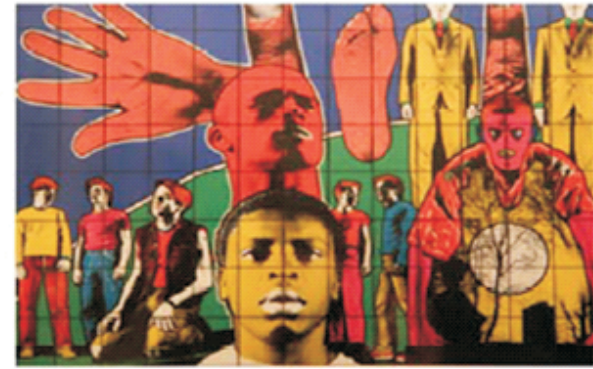

Gilbert and George

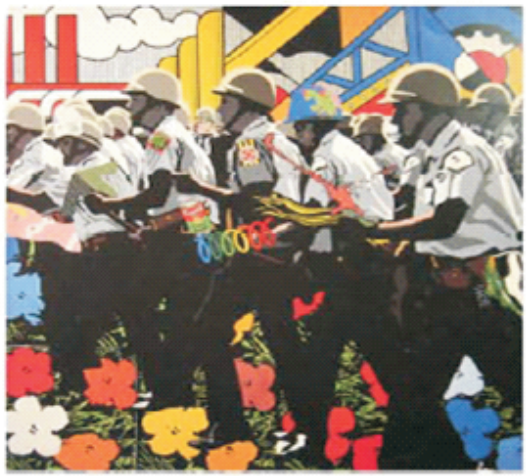

Equipo Crónica

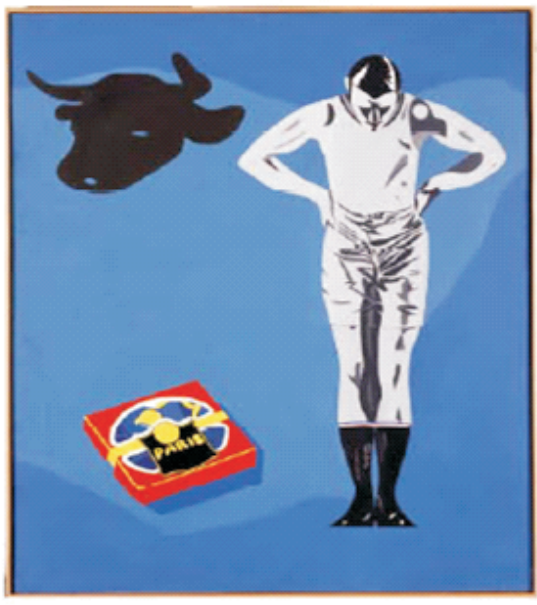

Eduardo Arroyo

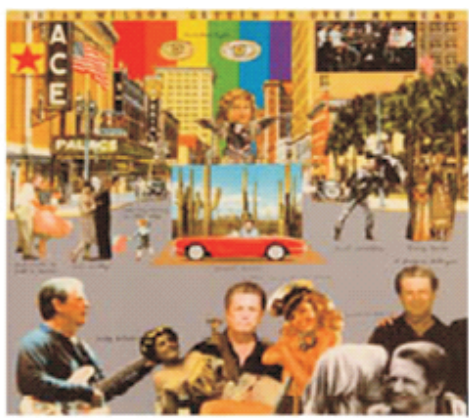

Peter Blake

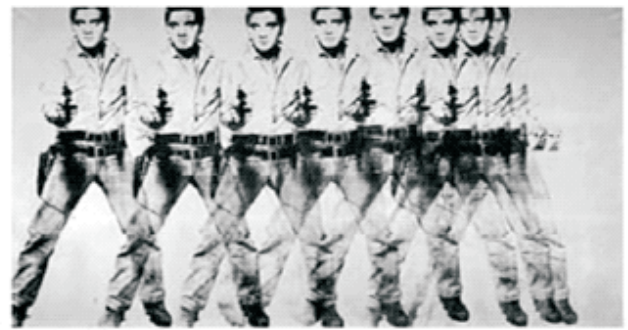

Andy Warhol

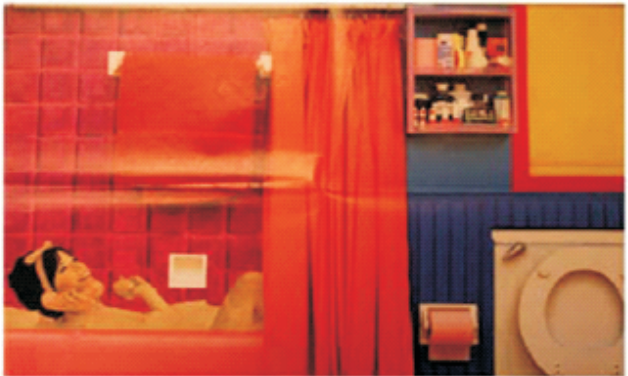

Tom Wesselmann

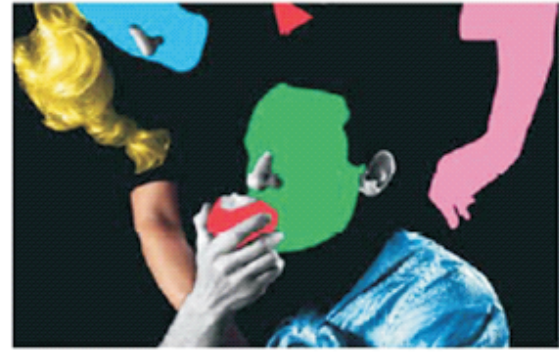

John Baldessari

En definitiva, podemos considerar esta etapa del arte occidental, que comprende dos décadas, como ciegamente «prodigiosas». La vanguardia cultural que tuvo sus focos principales en ciudades como París, Berlín, Viena, Milán, Moscú y Leningrado desvelaron vías creativas que hoy en día siguen mostrando su influencia. La fotografía ha sido un medio con un protagonismo especial en esta aventura. 